\title{
Gestão do Conhecimento e Gestão por Competências: estudo de caso no arquivo da Justiça do Trabalho de Londrina
}

\section{Knowledge Management and Competency Management: case study in the Londrina Jabor Justice archive}

\author{
Diana Marcela Ramirez Bernal, Leticia Gorri Molina ${ }^{1}$ \\ ${ }^{1}$ Universidade Estadual de Londrina - UEL, Londrina, PR, Brasil
}

Autor para correspondência/Mail to: Leticia Gorri Molina, leticiamolina@uel.br

Copyright (c) 2017 Bernal \& Molina. Todo o conteúdo da Revista (incluindo-se instruções, política editorial e modelos) está sob uma licença Creative Commons Atribuição-NãoComercial-Compartilhalgual 3.0 Não Adaptada. Ao serem publicados por esta Revista, os artigos são de livre uso em ambientes educacionais, de pesquisa e não comerciais, com atribuição de autoria obrigatória. Mais informações em http://revistas.ufpr.br/atoz/about/submissions\#copyrightNotice.

\begin{abstract}
Resumo
Introdução: A pesquisa analisou a importância da gestão por competências que são exigidas para aplicação da gestão do conhecimento no Arquivo da Justiça do Trabalho de Londrina.

Metodologia: foi utilizado o estudo de caso, aplicando-se como fontes de evidência para coleta de dados: o questionário com os servidores do Arquivo, observação direta e análise de documentação.

Resultados: evidenciou-se que as atividades no Arquivo são rotineiras e muitas baseadas na legislação do judiciário, o que prejudica o desenvolvimento de ideias que criem um ambiente gerador de conhecimento. Em relação às competências comportamentais, verificouse a ordem de importância, que foram apresentadas da mais para menos importante, são elas: autoconsciência, empatia, automotivação, autocontrole, e comunicação.

Conclusão: embora os servidores desempenhem algumas das atividades voltadas à gestão do conhecimento, elas não são registradas, visto que o foco das atividades realizadas no Arquivo está voltado para ações relacionadas a normas e leis que regem tais atividades.
\end{abstract}

Palavras-chave: Gestão do Conhecimento. Gestão por Competências. Arquivo. Justiça do Trabalho.

\begin{abstract}
Introduction: This research analyzed the importance of the competency management required to apply the knowledge management in the Labor Law Archive of Londrina.

Method: the case study was used, applying as a source of evidence for data collection: the questionnaire with the servers of the Archive, direct observation and analysis of the documentation.

Results: it was evidenced that the activities in the Archive are routine and many based on the legislation of the judiciary, which hinders the development of ideas that create a knowledge-generating environment. Regarding behavioral competences, there was an order of importance presented from the most important to least: self-awareness, empathy, self-motivation, self-control, and communication.

Conclusions: Although the servers perform some of the activities focused on knowledge management, they are not registered, since the focus of the activities carried out in the Archive is focused on actions related to norms and laws that govern such activities.
\end{abstract}

Keywords: Knowledge management. Management Competency. Archive. Work Justice.

\section{INTRODUÇÃO}

Com as mudanças sociais e econômicas, que ocorreram nos últimos anos nas empresas com respeito à forma de gerenciar seus recursos, tanto tangíveis quanto intangíveis, aparecem dois conceitos importantes para auxiliar nessa problemática: Gestão do Conhecimento (GC) e gestão por competências. Eles se integram mutuamente, com o propósito de atingir os objetivos estratégicos das organizações e obter um melhor posicionamento no mercado, por meio do reconhecimento e cuidado das pessoas (motivação, definição das competências).

A GC procura entender as relações no interior da organização, assim como da mesma com o ambiente externo, para usar os recursos disponíveis, com o propósito de melhorar produtos, processos e a relação com os clientes, agregando valor para os participantes do processo, e com isto possibilitar a geração de vantagens competitivas, por meio da criação de conhecimento como apoio às estratégias empresariais.

A Gestão de Competências busca motivar as pessoas para obterem as competências profissionais requeridas pelas empresas, com o propósito de aprimorar a competência organizacional e aumentar sua competitividade no mercado. Assim, a competência seria entendida como um conjunto de conhecimentos, habilidades e atitudes (individual), e também como um saber, como por exemplo saber fazer alguma atividade de maneira correta.

Após levantar essas evidências, pode se dizer que estudar a respeito da gestão do conhecimento e gestão de competências no Arquivo da Justiça do Trabalho de Londrina pode possibilitar a compreensão de como o conhecimento é tratado dentro da instituição. Desta forma, esta pesquisa teve como objetivo analisar as competências para aplicação da gestão do conhecimento, assim como as definições e características da gestão do conhecimento, as competências e a gestão por competências. Como objetivos específicos delimitaram-se: identificar as atividades realizadas pelo Arquivo da Justiça do Trabalho de Londrina relacionadas à gestão do conhecimento e verificar as competências dos funcionários para realizar a gestão do conhecimento. 
A metodologia empregada é de natureza qualitativa e quantitativa, do tipo descritiva, cujo método foi o Estudo de Caso (EdC). Para a análise dos dados, utilizou-se a técnica de Análise de Conteúdo, de Bardin (2011).

\section{GESTÃO DO CONHECIMENTO}

De modo geral, o conhecimento é aquilo que se sabe a respeito de algo que foi adquirido por meio de teorias, práticas, experiências, entre outros. É determinado por um ato intencional, da transformação de dados em informações, que serão analisadas para produzir novos saberes (Rosini, A; Palmisano, 2012).

No intuito de apresentar a relação dos conceitos que foram trabalhados neste estudo, é necessário iniciar com a definição de conhecimento. Segundo Choo (2003, p. 179), "[...] o conhecimento é também o resultado dos relacionamentos que a organização manteve ao longo do tempo com seus clientes, fornecedores e parceiros. Esses relacionamentos são quase sempre estratégicos para a organização, acelerando seu aprendizado [...]".

Silva Filho e de Benedicto (2008) explicam que o conhecimento é derivado de um conjunto de fatores, abrangendo as competências dos seus recursos humanos, e as competências da empresa como um todo, envolvendo sua estrutura organizacional, formas de gestão, processos, valores e cultura organizacional, entre outros.

Segundo Nonaka e Takeuchi (1997) as organizações inovam, porém, é importante considerar que para isso, deve-se conter informações de fora para dentro, para fazer frente às mudanças no ambiente, e dessa maneira, ir-se adaptando ao mesmo. À vista disso, as organizações criam novos conhecimentos e informação de dentro para fora, com o propósito de recriar seu meio e poder-se enfrentar a esse ambiente em transformação. Assim, podemos considerar que o conhecimento emoldura temas importantes para o desenvolvimento normal e cotidiano de qualquer organização.

Ainda segundo os autores citados, os indivíduos é que criam conhecimento, visto que a organização é formada por eles. Sendo assim, o conhecimento criado no ambiente organizacional cristaliza-se como parte da rede de conhecimentos da organização. Entendido isso, pode-se inferir que todas as empresas possuem conhecimento organizacional. Visto que, para elas se estruturarem, precisam de pessoas, que são a base fundamental de toda organização e são a razão de ser das mesmas, graças ao aporte dos seus conhecimentos, trabalho e habilidades no que desenvolvem na entidade (Nonaka \& Takeuchi, 1997).

Nonaka e Takeuchi (1997) defendem que, para realizar a conversão do conhecimento, é preciso a aplicação do modelo Socialização, Internalização, Conversão e Internalização (SECI), em que é necessário dar-se a interação social que se produz entre os dois tipos de conhecimento antes exposto. Sendo assim, os autores falam de quatro (4) etapas da conversão do conhecimento, são elas: Externalização, que pode ser entendida como os treinamentos profissionais, que compartilham conhecimento; Combinação, que é a maneira como entre iguais (pessoas com o mesmo cargo, mesmo perfil profissional) compartilham informações para a resolução de problemas locais, sem importar as barreiras geográficas (Skype, e-mail, etc.); Socialização, que é o clássico exemplo de Mestre aprendiz, no qual se aprende pelo exemplo e a observação, é muito importante para se inserir na organização e no cargo oferecido; Internalização, como sendo a habilidade que a pessoa tem para aplicar ou modificar as experiências e práticas aprendidas.

Para Silva Filho e de Benedicto (2008, p. 39) a GC envolve a compreensão das relações que existem internamente e externamente na organização, tendo o objetivo de utilizar os recursos disponíveis, no que tange a melhoria dos seus produtos e processos, na relação com clientes, e com isto, possibilitando aumento da vantagem competitiva e o crescimento sustentado da empresa. Nesse contexto, é importante saber que para que todas essas coisas aconteçam com sucesso, tanto na empresa quanto com os clientes, as mesmas devem alinhar-se com a estratégia da organização, com o intuito de que as pessoas que a compõem saibam o objetivo da mesma e direcionem seus esforços para obtê-la.

Valentim (2008, p. 4) considera que a GC:

[...] é um conjunto de atividades que visa trabalhar a cultura organizacional/informacional e a comunicação organizacional/informacional em ambientes organizacionais, no intuito de propiciar um ambiente positivo em relação à criação/geração, aquisição/apreensão, compartilhamento/ socialização e uso/utilização de conhecimento, bem como mapear os fluxos informais (redes) existentes nesses espaços, com o objetivo de formalizá-los, na medida do possível, a fim de transformar o conhecimento gerado pelos indivíduos (tácito) em informação (explícito), de modo a subsidiar a geração de ideias, a solução de problemas e o processo decisório em âmbito organizacional.

Em uma outra abordagem, Misra (2007) apresenta três dimensões da GC: a) Pessoas (P), que é composta por competências e comportamentos; b) Processos (P), que abrange estruturas internas para obtenção de resultados; e c) Tecnologia (T), que apoia e suporta a GC. Estas dimensões envolvem toda a organização, e com as quais se conseguiria o sucesso da mesma, já que estas se encontram ligadas e se complementam.

Como visto, o conhecimento, a experiência e habilidades das pessoas se complementam, isso a acontece porque para poder aplicar em qualquer atividade o conhecimento, deve-se contar com alguma habilidade para poder 
desenvolvê-la. Sendo assim, segundo Carbone, Tonet, Bruno, e Silva (2009), a GC e a gestão por competências são complementares na esfera da Administração Estratégica por meio da escola de posicionamento e a Teoria Baseada em Recursos, na qual a escola de posicionamento se sustenta em uma visão de fora para dentro da empresa, enquanto que a Teoria Baseada em Recursos atinge os processos internos (conhecimentos e competências) da organização.

\section{GESTÃO POR COMPETÊNCIAS}

Segundo Souza (2008), a gestão de pessoas vem se transformando grandemente, gaja vista a mudança de um modelo destacado na vigilância das pessoas, para um modelo salientado no seu desenvolvimento. Esse novo modelo é fundado na noção do desenvolvimento bilateral, ou seja, a pessoa contribui no crescimento da empresa e a companhia cria boas condições para o progresso das pessoas.

Segundo Dutra (2001, 2004), o progresso organizacional está cada vez mais focado na evolução das pessoas, as quais valorizam mais as condições oferecidas pela organização para o seu desenvolvimento. Esta cooperação está ligada ao nível de complexidade das tarefas encarregadas para eles, que já que vem sendo diretamente proporcionais, ou seja, quanto mais complexa é a atividade encomendada, maior é a contribuição que a pessoas faz. De acordo com isso, realmente o avanço do indivíduo, se caracteriza pela capacidade que ele tem de aceitar as responsabilidades mais complexas e não pelo fato de concentrar cada vez mais conhecimentos ou habilidades por meio da formação e a experiência (A. C. C. Fleury \& Fleury, 1999; Le Boterf, 2003; Zarifian, 2001).

De acordo com Amorim (2009), as empresas precisam se especializar cada vez mais, compreender melhor o ambiente em que estão inseridas, e identificar em quais áreas de negócio suas competências são verdadeiramente valorizadas. Para tal fim, há a necessidade de descobrir profissionais aptos que explorem todo o potencial dos profissionais. Dessa maneira, as competências prescritas, volta-se a ter cargos-chaves para conseguir diferenças competitivas por meio de uma Gestão de Pessoas eficiente.

De acordo com Souza (2008), pode-se analisar a competência sob diferentes fatores: um deles é a organização com competências próprias, que são provenientes da origem da mesma e do processo de desenvolvimento da empresa, as quais são materializadas no seu patrimônio de conhecimentos, que estabelece as vantagens competitivas da companhia no contexto em que se introduz. Para o autor, são as pessoas e as suas competências, que podem ou não serem valorizadas pela organização.

Segundo Dutra (2001, 2004) e M. T. L. Fleury e Fleury (2001), as competências humanas podem ser entendidas como um conjunto de conhecimentos (saber), habilidades (saber fazer) e atitudes (saber ser), que resultam em uma entrega ou em uma aplicação prática.

Para Le Boterf (2003), a competência não é um estado, e sim uma ação que resulta da combinação de recursos pessoais (conhecimentos, habilidades, qualidades, experiências, capacidades cognitivas, recursos emocionais etc.) e de recursos do meio (tecnologia, banco de dados, livros, relacionamentos etc.). A competência consiste em saber combinar esses recursos de forma a produzir uma ação competente. "O saber combinatório está no centro de todas as competências."(Le Boterf, 2003, p. 12). Portanto, se as pessoas sabem o que devem fazer, é mais fácil a empresa ser bem-sucedida, pois não terá perdas de tempo, dinheiro, e de investimento em aprendizagem, visto que as informações e os conhecimentos gerados terão um foco determinado para fortalecer a organização.

Além disso, a empresa e as pessoas aprenderão das experiências vivenciadas no exercício do trabalho cotidiano, ajudando assim à geração de conhecimento que enriquecerá a competitividade da companhia e conseguindo maior fidelidade dos trabalhadores, o que garante que o conhecimento seja mais duradouro.

Com as mudanças ocorridas nos modelos de trabalho e produção, inicia-se a preocupação, não somente pelas pessoas e pela forma como elas desenvolvem as suas atividades no trabalho, mas também se dá uma maior atenção às competências dos trabalhadores, para que sejam alinhadas com os objetivos da companhia, sendo de vital importância a gestão das mesmas.

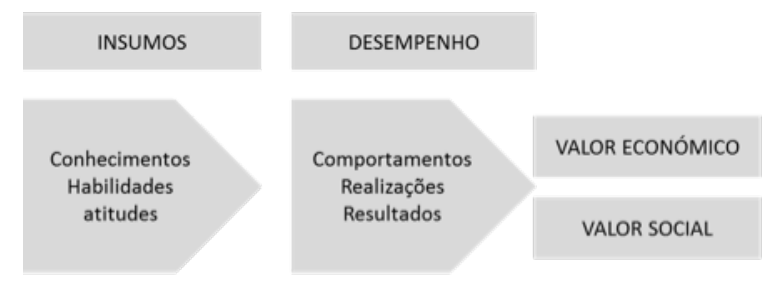

Figura 1. Competências como fonte de valor para o indivíduo e para a organização Fonte: Adaptado de M. T. L. Fleury e Fleury (2001, p. 30)

A gestão por competências pode ser entendida como uma parte importante da gestão e da estratégia organizacional, pois para ser desenvolvida corretamente na empresa, considera-se a missão, visão e os objetivos estratégicos, os 


\begin{tabular}{|c|c|}
\hline Autor & Modelos de gestão por competências \\
\hline $\begin{array}{l}\text { Brandão e Guimarães } \\
\text { (2001) }\end{array}$ & $\begin{array}{l}\text { É entendida como um processo circular, em que deve estar envolvida toda a orga- } \\
\text { nização e também é importante considerar que a mesma esteja articulada com a } \\
\text { estratégia organizacional, é dizer, com a missão, visão e os objetivos estratégicos. } \\
\text { Deve focar-se, não só na melhoria do desempenho profissional e organizacional, } \\
\text { mas também no desenvolvimento das pessoas em um sentido mais amplo; conse- } \\
\text { guindo que a organização ofereça diferentes oportunidades de crescimento a } \\
\text { seus integrantes, também valor econômico para a organização e um valor social } \\
\text { para o indivíduo, como se pode apreciar na Figura } 1 \text { abaixo. }\end{array}$ \\
\hline $\begin{array}{l}\text { Barbosa, Ferraz, e Lopes } \\
\text { (2002) }\end{array}$ & $\begin{array}{l}\text { Ressalta-se no panorama organizacional no momento em que se foca na eficiência } \\
\text { do indivíduo ante as demandas do mercado, que tem a ver com a produção e } \\
\text { resultados, assim como a capacitação e desenvolvimento. Para esses autores, o } \\
\text { complexo para a gestão de competências é assegurar lucros organizacionais bem } \\
\text { como compensar o empenho individual. }\end{array}$ \\
\hline Miranda (2004) & $\begin{array}{l}\text { Expõe a gestão por competências como um elemento estratégico na organização. } \\
\text { Identificando as competências das pessoas sem levar em consideração o posto } \\
\text { de trabalho. }\end{array}$ \\
\hline Brandão e Bahry (2005) & $\begin{array}{l}\text { "[...] propõe-se a orientar esforços para planejar, captar, desenvolver e avaliar } \\
\text { nos diferentes níveis da organização as competências necessárias à consecução } \\
\text { de seus objetivos"(p. 181). } \\
\text { Conforme Brandão e Guimarães (2001) e Brandão e Bahry a gestão por com- } \\
\text { petências procura planejar, selecionar, desenvolver e avaliar competências ne- } \\
\text { cessárias (humanas e profissionais) na organização para atingir os objetivos da } \\
\text { mesma. }\end{array}$ \\
\hline Gramigna (2007) & $\begin{array}{l}\text { Auxilia na avaliação do desempenho dos colaboradores na empresa, a fim de } \\
\text { melhorar as equipes e as relações no ambiente do trabalho. }\end{array}$ \\
\hline Lapolli (2010) & $\begin{array}{l}\text { É formada pela atenção dada ao ambiente externo para reflexionar no interior } \\
\text { da organização e agir para suportar as percepções em função das competências } \\
\text { existentes. }\end{array}$ \\
\hline
\end{tabular}

Quadro 1. Modelos de gestão por competências Fonte: Elaborado pelas autoras.

quais direcionam a companhia, conseguindo com isso a articulação do core do negócio. Assim como sendo uma ferramenta de motivação para que as pessoas consigam a competência profissional requerida pela companhia, adicionando habilidades por meio do trabalho desenvolvido na empresa e aumentando aquelas já existentes neles, com o propósito de acrescentar a competência organizacional, e aumentar a competitividade da companhia no mercado.

Para Lorza, Ortega, e Alvarado (2012), a gestão por competências surge pela necessidade das empresas de administrar seu capital humano, já que se faz indispensável prestar atenção as habilidades, conhecimentos, experiências e atitudes do empregado para enfrentar os desafios organizacionais, e dessa maneira demonstrar sua produtividade nesse ambiente que é competitivo e de alta mudança. Assim, esse conceito pretende valorizar o conhecimento e as habilidades das pessoas que desenvolvem os cargos nas empresas.

Além disso, pode ser considerada como uma ferramenta para motivar as pessoas para que elas consigam a competência profissional requerida pela companhia, adicionando habilidades por meio do desenvolvimento do trabalho na empresa e aumentando aquelas habilidades já existentes neles, com o propósito de acrescentar a competência organizacional, e aumentar de mesma maneira à competitividade da companhia no mercado.

Neste contexto, observa-se que tanto o conhecimento como a estratégia organizacional ajudam no cumprimento dos objetivos estabelecidos para a empresa. Porém, deve-se levar em conta a importância das pessoas, visto que são elas que agem nos processos corporativos com o intuito de conseguir os objetivos organizacionais. Para que as mudanças realmente aconteçam, Batalha e Silva (2001) defendem que as empresas se movimentam pelas pessoas que desenvolvem e usam as suas competências na medida em que realizam as suas tarefas. É nesse sentido que não se pode deixar do lado as competências humanas, assim como a gestão das mesmas.

Cabe ressaltar que a GC é uma ferramenta que apoia a criação de um clima de aprendizagem contínuo, com o propósito de que a gestão das competências se torne uma realidade. Isso não quer dizer que para administrar competência é necessário gerenciar conhecimento, porém, a GC possibilita a criação de um espaço favorável para tal. Assim, é importante lembrar que ao fazer a GC, serão administrados todos os ativos intangíveis que geram valor as empresas no momento de procurar capacidades essenciais diferenciadas, mas para isso, a direção da organização e a gerência de Recursos Humanos devem se moldar à sua estrutura e seus perfis atuais.

De igual maneira, a direção e a gerência, como responsáveis por administrar as pessoas, tendem a responder 
agilmente às mudanças, buscando soluções para estabelecer um diferencial competitivo, no qual a empresa deve reformular e inserir novas tecnologias, assim como inovar nas práticas gerenciais, apreciando o sujeito como distintivo competitivo. Surgindo assim, a necessidade de vincular a Gestão de Competências como uma prática comum na administração diária e estratégica de pessoas nas empresas.

Costa (2004) e Bellinghini (2004) estabelecem que a Gestão de Pessoas por Competências está se fortalecendo como base de suporte na geração de vantagens competitivas e a integração das pessoas às estratégias organizacionais. Em tempos de globalização da economia, as empresas fundamentam sua competitividade no conhecimento e com isso, o foco passa a ser voltado para as pessoas que compõem a organização Benetti e Pantoja (2008). Assim, entende-se que a qualidade competitiva da companhia está condicionada à faculdade de aprender facilmente, bem como na capacidade de criar conhecimento capaz de gerar inovação de processos para fabricar produtos e serviços sobressalentes, ou de maior reconhecimento no mercado.

Segundo Tejada Zabaleta (2011), cabe à gestão de pessoas se certificar de qual a capacidade humana pode se relacionar com os processos produtivos eficientes, eficazes e efetivos da companhia. Assim, é importante que os diretores ou gerentes das empresas alcancem conhecimentos que lhes ajudem a descobrir, sustentar, desenvolver, testar e motivar o talento dos seus colaboradores e o próprio, como forma de mudança organizacional. É nesse instante que se faz importante a GC, com a qual se procura aproveitar o conhecimento, o talento e a experiência coletiva das pessoas que fazem parte da organização.

\section{ESTUDO DE CASO: ARQUIVO DA JUSTIÇA DO TRABALHO DE LONDRINA}

O Tribunal Regional do Trabalho da $9^{a}$ Região (TRT-PR) é um órgão do Poder Judiciário com sede em Curitiba e jurisdição no Estado do Paraná, tem como missão solucionar os conflitos provenientes das relações trabalhistas com justiça e efetividade na entrega da prestação jurisdicional. Em sua visão, procura ser referência na distribuição de justiça; e finalmente está regido pelos valores de ética, respeito, acessibilidade, transparência, credibilidade, inovação, efetividade, comprometimento, justiça social, duração razoável do processo e responsabilidade socioambiental (Tribunal Regional do Trabalho do Paraná, 2016).

Dentre os seus processos, o TRT conta com a Gestão Documental, a qual é formada pela unidade de Coordenadoria de Gestão Documental, Arquivo e Memória, que responde pela guarda, conservação e tratamento de todo acervo de autos judiciais e documentos administrativos que se encontram em arquivo intermediário e permanente. Para tanto, trabalha diretamente com o arquivo de Curitiba, com as Seções de Arquivo, Gestão Documental e Memória de Maringá e Londrina e com a Seção de Memória, consoante disposto no ato 253/2013, referendado pelo Órgão Especial na RA153/2013.

O Arquivo da Justiça do Trabalho de Londrina é formado por dezenove (19) varas (áreas de trabalho) vinculadas ao município. No tribunal são recebidos dois tipos de processos, aqueles que são nomeados de processos definitivos e os de processos provisórios, esse último, entendido quando as empresas quebram financeiramente.

A coleta de dados referentes à aplicação do modelo foi realizada com servidores selecionados da área pesquisada, cada um deles respondendo a um questionário, desenvolvendo desse modo, uma avaliação das competências de cada um. Para tanto, foi analisado, como documento, o edital N ${ }^{\circ}$ 01/2015 de abertura de inscrições para concurso, depois realizada a observação direta, a aplicação do questionário. A partir da coleta dos dados, foram realizadas análises de inferência com base no referencial teórico estabelecido e discutido na pesquisa, assim como em relação à percepção e observações realizadas pela pesquisadora no local. Como método de análise dos dados, foi utilizado o método Análise de Conteúdo (ADC), mais especificamente a técnica Análise Categorial (AC), de Laurence Bardin (2004). Bardin (2002, p. 32) define a ADC como:

Um conjunto de técnicas de análise das comunicações visando obter indicadores (quantitativos ou não) por procedimentos, sistemáticos e objetivos de descrição do conteúdo das mensagens, que permitam a inferência de conhecimentos relativos as condições de produção/recepção (variáveis inferidas) destas mensagens.

Segundo Flick (2009, p. 291), na AC "[...] uma das características essenciais é a utilização de categorias, as quais são normalmente obtidas a partir de modelos teóricos: as categorias são levadas para o material empírico e não necessariamente desenvolvidas a partir deste [...] o objetivo aqui é reduzir o material".

As categorias foram definidas a priori, de acordo com os objetivos da pesquisa e definição do corpus teórico, que culminou nos instrumentos de pesquisa que serão aplicados aos sujeitos. Assim como, as categorias definidas foram: Gestão do Conhecimento - colaboração, compartilhamento/socialização, registro da informação, reuso da informação, disseminação da informação; Competência - importância e reconhecimento por parte dos colaboradores; Gestão por Competência-importância, e desenvolvimento na área.

A pesquisa é de abordagem qualitativa e quantitativa. De acordo com o seu objetivo, é descritiva, a qual segundo Gil (1991), procura descrever as características de determinada população ou fenômeno ou o estabelecimento 
de relações entre variáveis. Abrange o emprego de técnicas para a coleta de dados, tais como questionário e observação sistemática, que se assume, em geral, a forma de Levantamento.

Como instrumentos de coleta de dados, foram aplicados:

- Questionário, constituído de questões fechadas, estruturado a partir das categorias estabelecidas a priori, aplicado aos 4 (quatro) servidores do Arquivo da Justiça do Trabalho;

- Análise da documentação, ou seja, nos documentos gerados a partir das ações realizadas pelo TRT aplicável para o Arquivo da Justiça do Trabalho, assim como normatividade onde estão localizados e que tipo de informação contém. Neste caso, o documento analisado foi o "edital_de_abertura_do_concurso_2015 - edital $n^{\circ}$ 01/2015 de abertura de inscrições";

- Observação direta com a aplicação de um check list, que ajudaram na obtenção de informação das atividades realizadas pelos servidores no Arquivo da Justiça do Trabalho. A análise dos documentos ressaltou pontos relevantes para a rotina do grupo, como: normas, edital de concurso, entre outros identificados no estudo. Com isso, se realizou a análise, interpretação e reflexão dos conteúdos do documento.

Com relação aos procedimentos, trata-se de um Estudo de Caso (EdC), que conforme Araújo, Pinto, Lopes, Nogueira, e Pinto (2008) e Yin (2010), é adequado quando se pretende entender, descobrir ou expor eventos ou fenômenos e contextos sociais complexos, nos quais estão simultaneamente envolvidos diversos fatores. Proporciona a melhor escolha de método de pesquisa para poder compreender um pouco melhor os acontecimentos dos diversos problemas na vida real sejam fatos individuais, sociais, organizacionais, grupais, políticos e relacionados.

\section{ANÁLISE E DISCUSSÃO DOS RESULTADOS DE PESQUISA}

A partir da aplicação do questionário, procurou-se primeiramente averiguar se existe GC no Arquivo da Justiça do Trabalho, bem como quais as competências necessárias, identificadas para as pessoas que ali trabalham atuarem no referido processo. A primeira parte do questionário coletou informações referentes à GC e a segunda parte coletou informações sobre as competências.

Em relação à categoria Gestão do Conhecimento, delimitado como colaboração, compartilhamento/socialização, registro da informação, reuso da informação, disseminação da informação, os indivíduos pesquisados consideram muito importante a demanda por informações para a realização das atividades na unidade, devido a importância que nas atividades de conciliação entre demandante e demandado. Quanto as atividades relacionadas à GC, a instituição estimula o diálogo e a reflexão (Externalização); a realização de fóruns, comitês funcionais, etc. (Combinação); estimular a prática, estágio técnico, etc. (Internalização), além da experiência direta, por meio de contato e troca de informações e ideias entre os funcionários (Socialização). Quanto às características que os profissionais que participam dos processos de GC precisariam, identificaram: Buscar informação de forma crítica para a tomada de decisões; Criar empatia com os outros para facilitar a interação; Estimular a colaboração no ambiente te trabalho; e Cooperar como o desenvolvimento de atividades comuns.

Com respeito às atividades da GC - Geração, Codificação e Transferência - Silva, Soffner e Pinhão (2004), as definem da seguinte maneira: Geração, composta pela aquisição, recursos dedicados, fusão, adaptação e redes do conhecimento. A Codificação, conforme os autores, consiste na representação do conhecimento de maneira que o mesmo possa ser acedido e transferido. Segundo os autores, essa atividade é intrínseca aos aspectos tecnológicos. Um dos objetivos da codificação do conhecimento é saber onde encontrá-los, mesmo existindo muita informação. A Transferência, segundo eles, é a principal na gestão do conhecimento, já que, o conhecimento só se torna ação se flui no meio da organização e na sua disponibilidade onde e quando for necessário.

No caso do Arquivo da Justiça do Trabalho de Londrina cumprem-se as três atividades, no que tange a geração do conhecimento, apreciando-se a existência de redes de conhecimento, além da existência de grupos de pessoas que possuem interesses comuns, que se comunicam por meios, na maioria das vezes, informacionais, e assim, criam e compartilham conhecimento, conforme defendem os autores acima citados (Silva, Soffner, \& Pinhão, 2004). Com relação a codificação, contam com um sistema que permite acessar ao conhecimento, e finalmente transferi-lo para quem precise.

A categoria Competência, delimitada como importância e reconhecimento percebidos por parte dos colaboradores, tiveram como resultados: que a instituição compartilha a informação e experiências internas por meio da promoção de seminários internos entre profissionais, mesas redondas e desenvolvimento de projetos em equipes multidisciplinares, assim como incentiva aos colaboradores terem acesso facilitado aos seus superiores, com objetivo de compartilhar suas ideias, e também são incentivados e até subsidiados em relação aos estudos pessoais dos colaboradores, que podem ser disseminados na instituição.

Com relação à análise das competências técnicas e das competências comportamentais, as comportamentais foram agrupadas com base no conceito da Inteligência Emocional (Goleman, 1996), com o intuito de ter uma maior compreensão das mesmas. As competências técnicas são aquelas que se referem ou que foram adquiridas 
por meio da educação formal, treinamentos e experiência profissional. De igual maneira e conforme Van Arken (2017), as competências técnicas e comportamentais se referem às habilidades específicas relacionadas com o desempenho adequado de cargos voltados á área técnica ou de uma função específica e que descrevem as habilidades de colocar na prática os conhecimentos técnicos e específicos muito ligados ao sucesso da execução técnica do cargo.

Uma vez analisados os dados coletados em relação às competências técnicas, observa-se que para os Servidores do Arquivo da Justiça do Trabalho de Londrina é imperativo o cumprimento das normas e leis arquivistas, seguido de: receber documentos/informação, eficiência no trabalho, eficácia na obtenção de resultados, organização no ambiente de trabalho, disseminar/compartilhar informação, pesquisar documentos/informação, realizar procedimentos técnicos para o tratamento de documentos/informação, além do domínio básico de informática e sistemas de informação. Em última instância, estão as competências de elaboração de relatórios/atas a gerencia, controle administrativo e capacidade de planejar e organizar.

Por meio dos dados coletados por meio do questionário, observou-se que as competências comportamentais de maior importância para os servidores do Arquivo da Justiça do Trabalho são: Adaptabilidade as mudanças; Criatividade; Capacidade de negociação; Saber lidar com conflitos; Capacidade para buscar conhecimento; Autodesenvolvimento; Automotivação; Iniciativa; Relação interpessoal; Capacidade de comunicação; e Trabalhar em equipe.

Por Grupo de Competências, considerou-se 20 (vinte) competências comportamentais, que foram agrupadas com base no modelo de Daniel Goleman sobre inteligência emocional. Vale ressaltar a definição de Goleman (1996, p. 31) para cada uma das habilidades: Autoconsciência: "[...] é a capacidade de reconhecer um sentimento no mesmo momento em que ele aparece. [...]".; Autocontrole: "Capacidade de controlas as nossas emoções."; Automotivação: "Capacidade de se motivar a si mesmo."; Empatia: "Reconhecimento das emoções dos outros."; Comunicação: "[...] habilidade para nos relacionar adequadamente com as emoções dos outros."

Em relação aos dados coletados, observa-se que o grupo de competências comportamentais segue a seguinte ordem de mais importante para menos importante, para os servidores do Arquivo da Justiça do Trabalho: autoconsciência, empatia, automotivação, autocontrole, e finalmente a comunicação. Uma vez realizada a análise de conteúdo com base na percepção das respostas dadas no questionário, foi possível identificar que para os servidores do Arquivo da Justiça do Trabalho a categoria que deve primar é o compartilhamento de informação/conhecimento. Para eles, é relevante auxiliar as pessoas que procuram os processos trabalhistas, com o intuito de conciliar as demandas entre as partes.

A categoria Gestão por Competência, considerada como importância e desenvolvimento na área, foi verificada por meio da análise da documentação, no caso o documento "edital_de_abertura_do_concurso_2015 - edital no $01 / 2015$ de abertura de inscrições".

Por meio desse documento, estudou-se a descrição das atribuições básicas dos cargos/áreas/especialidades do TRT, focado nos cargos do Arquivo do Trabalho de Londrina, em que se percebeu que as funções desenvolvidas pelos servidores no arquivo, para o único cargo de Técnico Judiciário - Área Administrativa foi delimitada: Prestar apoio técnico e administrativo pertinente às atribuições das unidades organizacionais; Executar tarefas de apoio à atividade judiciária; Arquivar documentos; efetuar tarefas relacionadas à movimentação e à guarda de processos e documentos; Atender ao público interno e externo; Classificar e autuar processos; Realizar estudos, pesquisas e rotinas administrativas; Redigir, digitar e conferir expedientes diversos e executar outras atividades de mesma natureza e grau de complexidade.

Evidenciou-se que as atividades são rotineiras e não há espaço para o desenvolvimento de ideias que criem um ambiente gerador de conhecimento, já que as tarefas desempenhadas pelos servidores do Arquivo da Justiça do Trabalho de Londrina são específicas.

Em relação à observação direta, obtiveram-se dados de determinados aspectos da realidade, sendo realizada uma observação sistemática, por meio da aplicação de um check list. Assim, identificou-se que o propósito principal do Arquivo do Trabalho de Londrina "Realizar a organização da documentação para sua acessibilidade", apresentado na Figura 2.

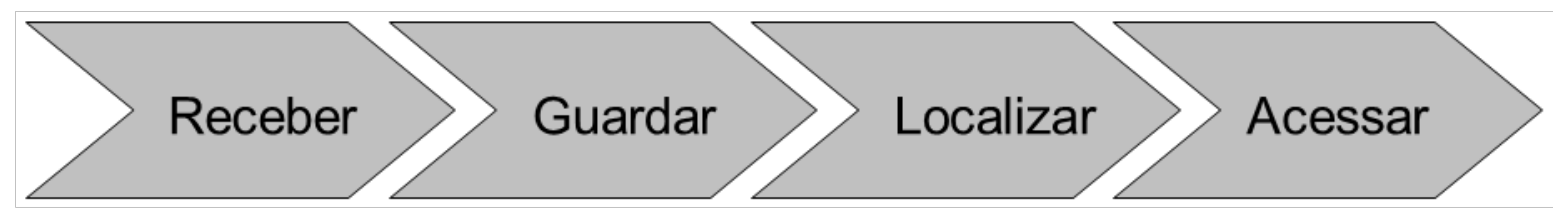

Figura 2. Processo do Arquivo do Trabalho de Londrina.

Fonte: As autoras.

Esse processo pode ser comparado ao Modelo Processual de Choo (2003): Identificação de necessidades de informação; Coleta de informação; Organização e armazenamento; Distribuição e Uso da informação. 
Observou-se que a identificação de necessidades de informação e a coleta de informação estão relacionadas ao receber, o que pode ser entendido como aquele momento em que os usuários solicitam informação e os servidores procedem à coleta. Seguidamente a organização e armazenamento, que tem seu par no processo nomeado como guardar, faz referência ao acervo em que chegam os processos das outras varas, que se devem organizar conforme as diretrizes existentes ali. A distribuição está relacionada ao localizar, referindo-se à procura de informação que os usuários requerem, como também, colocar os processos que chegam das outras varas, no local certo; finalmente, o uso da informação relaciona-se com acessar, que faz referência a possuir conhecimento da informação solicitada e dada pelos servidores do Arquivo da Justiça do Trabalho de Londrina. Importante levar em consideração que ela está regida pela Lei de Acesso à Informação (LAI), a Lei $n^{\circ}$ 12.527/2011, que regulamenta o direito constitucional de acesso às informações públicas.

\section{CONSIDERAÇÕES FINAIS}

O objetivo geral da pesquisa foi analisar as competências para aplicação da gestão do conhecimento, bem como as definições e características da gestão do conhecimento, as competências e a gestão por competências. Como objetivos específicos delimitaram-se: identificar as atividades realizadas pelo Arquivo da Justiça do Trabalho de Londrina relacionadas à gestão do conhecimento; verificar as competências dos funcionários para realizar a gestão do conhecimento.

Assim sendo, afirma-se que o objetivo relacionado com a identificação das atividades realizadas pelo Arquivo da Justiça do Trabalho de Londrina relacionadas à GC, foi alcançado, ainda que as atividades identificadas através da observação (aplicação do check list), e a análise do Edital, fazerem parte da GC, algumas delas poderiam ser formalizadas, como por exemplo, o registro das lições aprendidas.

De acordo com o documento analisado, as responsabilidades de cada um dos servidores estão bem definidas para o cargo que desempenham, e os mesmos cumprem com o fluxo de processo estabelecido para a área. Da mesma forma, se evidencia que as relações sociais (tanto para a realização do trabalho como no ambiente laboral) são fortes e podem ser estimuladas para gerar uma GC. Ainda que as pessoas desempenhem o papel principal com respeito ao conhecimento, concerne à instituição gerar as condições apropriadas para o ótimo uso desse recurso, visto que são os objetivos e as estratégias, as normas e leis de armazenamento e a disposição do trabalho, maneiras da instituição de interferir e melhorar a obtenção e o compartilhamento do conhecimento.

Vale ressaltar que foi alcançado o objetivo alusivo à verificação das competências dos funcionários para realizar a GC, porém, devido as atividades desenvolvidas pelos servidores serem mais rígidas e regidas pela lei para o funcionamento da área, não existe muito espaço para desenvolver ações mais adequadas e complementares a GC, embora nos dados analisados, eles considerassem que o compartilhamento da informação e do conhecimento é o mais importante para eles.

No que se refere às competências comportamentais, observou-se que os servidores acham importante a responsabilidade e cumprimento dos deveres, assim como interagir com os usuários e compartilhar conhecimento, abrangendo algumas das competências necessárias para desenvolver a GC.

Conforme o agrupamento realizado para uma parte da análise das competências comportamentais, com base na inteligência emocional, infere-se que liderou a autoconsciência das responsabilidades que eles têm para desenvolver o seu trabalho, seguido da empatia que devem ter para tratar com os usuários do Arquivo, e entre eles mesmos. Embora os servidores também considerarem em ordem de importância a automotivação, a característica da instituição não conta com esse espaço para desenvolvê-la e aplicá-la na área. Por último, o autocontrole e a comunicação são os grupos das competências comportamentais que os servidores do Arquivo da Justiça do Trabalho de Londrina acharam menos importantes. Assim, considera-se que no Arquivo da Justiça do Trabalho não há a predominância de ações que envolvem a GC.

Para concluir, apresentam-se as considerações sobre a legitimidade dos resultados alcançados na pesquisa. Vale ressaltar, que o aporte que a GC poderia trazer ao Arquivo da Justiça do Trabalho de Londrina seriam o de criar uma cultura voltada para o conhecimento, um capital humano que conte com uma capacidade individual de agir na instituição, com competências adequadas para a GC, com educação formal, experiência e na qual se apreciem os valores da pessoa, e que agreguem valor ao cliente (inovação, atitude de colaboração); um capital de clientes (usuários internos e externos). Assim como uma cultura de aprendizagem, dinâmica colaborativa no interior da instituição, condições tecnológicas mínimas adequadas e manutenção do recurso humano qualificado. 


\section{REFERÊNCIAS}

Amorim, T. N. G. F. (2009). Gestão de pessoas no agronegócio. In A. A. Callado (Ed.), Agronegócio (2a. ed.). São Paulo: Atlas.

Araújo, C., Pinto, E., Lopes, J., Nogueira, L., \& Pinto, R. (2008). Estudo de caso: Métodos de Investigação em Educação. Instituto de Educação e Psicologia, Universidade do Minho. Recuperado em 2016-02-13, de http://grupo4te .com.sapo.pt/estudo\{_\}caso.pdf

Barbosa, A. C. Q., Ferraz, D. M., \& Lopes, D. P. T. (2002). Competências nas organizações: o discurso e a prática na gestão de pessoas. Encontro Anual da Associação Nacional dos Programas de Pós-Graduação em Administração, 26.

Bardin, L. (2002). Análise de conteúdo. São Paulo: Edições 70.

Bardin, L. (2004). Análise de conteúdo (3a. ed.). São Paulo: Edições 70.

Bardin, L. (2011). Análise de conteúdo. São Paulo: Edições 70 .

Batalha, M. O., \& Silva, A. L. (2001). Gerenciamento de sistemas agroindustriais: definições e correntes metodológicas. In Gestão agroindustrial (2a. ed.). São Paulo: Atlas.

Bellinghini, M. F. (2004). Estratégias de acumulação de competências tecnológicas e aprimoramento de performance técnico-econômica em operadoras de telefonia fixa: a experiência da Telemar Norte Leste S.A. In Xxviii encontro anual da anpad. Curitiba: ANPAD.

Benetti, L., \& Pantoja, M. J. (2008). A gestão por competências na perspectiva da aprendizagem organizacional o caso de uma empresa pública de grande porte. In Xxxii encontro anual da anpad. ANPAD.

Brandão, H. P., \& Bahry, C. P. (2005). Gestão por competências: métodos e técnicas para mapeamento de competências. Revista do Serviço Público, 56(2), 179-194.

Brandão, H. P., \& Guimarães, T. d. A. (2001). Gestão de competências e gestão de desempenho: tecnologias distintas ou instrumentos de um mesmo construto? Revista de Administração de empresas, 41(1), 8-15.

Carbone, P. P., Tonet, H. C., Bruno, J. R. d. S., \& Silva, K. I. B. E. (2009). Gestão por competências. Rio de Janeiro: Editora FGV.

Choo, C. W. (2003). A organização do conhecimento: como as organizações usam a informação para criar significado, construir conhecimento e tomar decisões. Senac São Paulo.

Costa, M. A. S. (2004). Gestão de pessoas por competências e administração estratégica: o caso de uma empresa do pólo petroquímico de Camaçari. In Xxviii encontro anual da anpad. Curitiba: ANPAD.

Dutra, J. S. (2001). Gestão por competências: um modelo avançado para o gerenciamento de pessoas. São Paulo: Editora Gente.

Dutra, J. S. (2004). Competências: conceitos e instrumentos para a gestão de pessoas na empresa moderna. São Paulo: Atlas.

Fleury, A. C. C., \& Fleury, M. T. L. (1999). Estratégias empresariais e formação de competências. São Paulo: Atlas.

Fleury, M. T. L., \& Fleury, A. (2001). Construindo o conceito de competência. Revista de administração contemporânea, 5(SPE), 183-196.
Flick, U. (2009). Métodos de pesquisa: introdução à pesquisa qualitativa (3a. ed.). Porto Alegre.: Artmed.

Gil, A. C. (1991). Como elaborar projetos de pesquisa. São Paulo: Atlas.

Goleman, D. (1996). Inteligência emocional. São Paulo: Kairós.

Gramigna, M. R. (2007). Modelo de competências e gestão de talentos (2a. ed.). São Paulo: Pearson Prentice Hall.

Lapolli, J. (2010). Mapeamento de competências: teoria e prática. Florianópolis: Pandion.

Le Boterf, G. (2003). Desenvolvendo a competência dos profissionais. Porto Alegre: Artmed.

Lorza, A. F. M., Ortega, A. M. D., \& Alvarado, P. A. L. (2012). Fundamentos de un sistema de gestión humana por competencias para soportar la estrategia organizacional en una pyme del sector de la industria de las artes gráficas en Cali (Colombia). Estudios Gerenciales: Journal of Management and Economics for Iberoamerica, 28(122), 121-138.

Miranda, S. V. (2004). Identificando competências informacionais. Ciência da informação, 33(2), 112-122. doi: 10.1590/S0100-19652004000200012

Misra, D. C. (2007). Ten guiding principles for knowledge management in e-government in developing countries. National Productivity Council New Delhi (IN). Recuperado em 2016-11-05, de http://incubadora.periodicos.ufsc.br/ index.php/IJKEM/article/viewFile/2778/3471

Nonaka, I., \& Takeuchi, H. (1997). Criação de conhecimento na empresa: como as empresas japonesas geral a dinâmica da inovação. Rio de Janeiro: Campus.

Rosini, A; Palmisano, A. (2012). Administração de sistemas de informação e a gestão do conhecimento (2a. ed.). São Paulo: Cengage Learning.

Silva, R. V., Soffner, R., \& Pinhão, C. (2004). A Gestão do Conhecimento. In R. V. Silva \& A. Neves (Eds.), Gestão de empresas na era do conhecimento. São Paulo: Serinews.

Silva Filho, C. F. d. S., \& de Benedicto, G. C. (2008). Aprendizagem e gestão do conhecimento: fundamentos teóricos $e$ experiências práticas. Campinas: Alínea.

Souza, J. (2008). Formação e desenvolvimento de quadros técnico para o setor siderúrgico. Brasília: Centro de Gestão e Estudos Estratégicos.

Tejada Zabaleta, A. (2011). Los modelos actuales de gestión en las organizaciones. Gestión del talento, gestión del conocimiento y gestión por competencias. Psicología desde el Caribe, 12, 115-133.

Tribunal Regional do Trabalho do Paraná. (2016). Quem somos. Recuperado em 2016-02-13, de http://www.trt9.jus .br $/$ portal $/$ pagina. $x h t m l$ secao $=45\{\&\}$ pagina $=$ INICIAL

Valentim, M. L. P. (2008). Gestão da Informação e Gestão do Conhecimento em ambientes organizacionais (v. 1) (n. 1). Universidade Federal de Paraiba. Recuperado em 15.10.2016, de http://inseer.ibict.br/ancib/index.php/tpbci article/view/3/14

Van Arken, H. (2017). Pedagogía docente. Recuperado em 2017-02-02, de https://pedagogiadocente.wordpress.com/ competencias/competencias-tecnicas/

Yin, R. K. (2010). Estudo de caso: planejamento e métodos (4a. ed.). Porto Alegre: Bookman.

Zarifian, P. (2001). Objetivo competências. São Paulo: 
Atlas.

Como citar este artigo (APA):

Bernal, D. M. R., \& Molina, L. G. (2017). Gestão do Conhecimento e Gestão por Competências: estudo de caso no arquivo da Justiça do Trabalho de Londrina. AtoZ: novas práticas em informação e conhecimento, 6(2), 4 - 13. Recuperado de: http://dx.doi.org/10.5380/ atoz.v6i2.57875 